\title{
Curcumin derivative C817 inhibits proliferation of imatinib-resistant chronic myeloid leukemia cells with wild-type or mutant Bcr-Abl in vitro
}

\author{
Li-xian WU ${ }^{1,2,3, *}$, Ying WU ${ }^{2,3}$, Rui-jia CHEN ${ }^{1,2}$, Yang LIU ${ }^{2,3,4}$, Li-sen HUANG ${ }^{1,2}$, Li-guang LOU ${ }^{5}$, Zhi-hong ZHENG ${ }^{6}$, \\ Yuan-zhong $\mathrm{CHEN}^{6}$, Jian-hua $\mathrm{XU}^{1,2,3, *}$ \\ ${ }^{1}$ Department of Pharmacology, ${ }^{2}$ Institute of Materia Medica, ${ }^{3}$ Fuijan Key Laboratory of Natural Medicine Pharmacology, ${ }^{4}$ Department \\ of Pharmacochemistry, School of Pharmacy, Fujian Medical University, Fuzhou 350004, China; ${ }^{5}$ Shanghai Institute of Materia Medica, \\ Shanghai 201203, China; ${ }^{6}$ Fujian Institute of Hematology, Union Hospital, Fujian Medical University, Fuzhou 350001, China
}

Aim: To find new kinase inhibitors that overcome the imatinib resistance in treatment of chronic myeloid leukemia (CML), we synthesized C817, a novel derivative of curcumin, and tested its activities against wild-type (WT) and imatinib-resistant mutant Abl kinases, as well as in imatinib-sensitive and resistant CML cells in vitro.

Methods: 32D cells harboring WT or mutant Abl kinases (nucleotide binding P-loop mutants Q252H, Y253F, and imatinib contact residue mutant T315I), as well as K562/G01 cells (with whole Bcr-Abl gene amplication) were tested. Kinase activity was measured using Kinase-Glo Luminescent Kinase Assay Platform in recombinant WT and mutant (Q252H, Y253F, and T315I) Abl kinases. Cell proliferation and apoptosis were examined using MTT assay and flow cytometry, respectively. The phosphorylation levels of Bcr-Abl initiated signaling proteins were analyzed using Western blotting. Colony forming units (CFU) growth and long term culture-initiating cells (LTC-ICs) were used to test the effects of C817 on human leukemia progenitor/stem cells.

Results: C817 potently inhibited both WT and mutant (Q252H, Y253F, and T315I) Abl kinase activities in a non-ATP competitive manner with the values of $\mathrm{IC}_{50}$ at low nanomole levels. In consistent with above results, $\mathrm{C} 817$ suppressed the growth of both imatinib-sensitive and resistant CML cells, including wild-type K562, K562/G01, 32D-T315I, 32D-Q252H, and 32D-Y253F cells with the values of IC ${ }_{50}$ at low micromole levels. C817 (0.5 or $1 \mu \mathrm{mol} / \mathrm{L})$ dose-dependently inhibited the phosphorylation of Bcr-Abl and downstream proteins STAT-5 and CrkL in imatinib-resistant K562/G01 cells. Furthermore, C817 significantly suppressed CFU growth and LTC-ICs, implicating that $\mathrm{C} 817$ could eradiate human leukemia progenitor/stem cells.

Conclusion: C817 is a promising compound for treatment of CML patients with Bcr-Abl kinase domain mutations that confer imatinib resistance.

Keywords: chronic myelogenous leukemia; imatinib resistance; Bcr-Abl; mutantion; curcumin; C817; leukemia stem cell

Acta Pharmacologica Sinica (2014) 35: 401-409; doi: 10.1038/aps.2013.180; published online 3 Feb 2014

\section{Introduction}

$\mathrm{Bcr}-\mathrm{Abl}$ protein, because of its high tyrosine kinase activity in $90 \%$ of chronic myeloid leukemia (CML) cases, has become promising target to synthesize small molecules that inhibit its kinase activity in leukemic cells without adversely affecting the normal cells ${ }^{[1,2]}$. Clinical remission is usually achieved in early-stage of CML with the imatinib by occupying ATP-site of Abl kinase, and it is now a first-line therapy for the majority of CML patients because of its high efficacy level and rela-

\footnotetext{
* To whom correspondence should be addressed.

E-mail xjh@mail.fjmu.edu.cn (Jian-hua XU); wlx-lisa@126.com (Li-xian WU)

Received 2013-08-09 Accepted 2013-11-15
}

tively mild side effects. Despite outstanding clinical results, imatinib-resistant leukemia and clinical relapse eventually emerge.

Mechanisms of resistance to imatinib include mutations of the Bcr-Abl kinase domain, the amplification of the $B c r-A b l$ gene, increased expression of the Bcr-Abl protein, increased expression of the $m d r-1$ gene-encoded P-glycoprotein, and insensitivity of leukemia stem cells to imatinib ${ }^{[3-5]}$. Clinically observed mutations have been identified within several regions of the Bcr-Abl kinase domain. In this study, we examined 3 kinase domain variants: Q252H, Y253F, and T315I, and $B c r-A b l$ gene amplification. These variants contain several functionally distinct kinase domain regions, including the nucleotide binding P-loop (Q252H, Y253F), 2 imatinib mesyl- 
ate contact residues (Y253F and T315I), and the whole Bcr-Abl gene amplication.

There is considerable interest in developing alternative $\mathrm{Abl}$ kinase inhibitors capable of inhibiting the Bcr-Abl kinase domain mutants observed in relapsed patients. An array of novel ATP-competitive and non-ATP-competitive therapies with distinct mechanisms of action is undergoing preclinical. Two recently approved drugs nilotinib and dasatinib are able to override the majority of the imatinib resistance mutations with the exception of T315I mutation, which is situated in the middle of the ATP-binding cleft ${ }^{[6-12]}$. GNF-2, a selective allosteric Bcr-Abl inhibitor, is new pharmacological modality to overcome resistance to ATP-site inhibitors of Bcr$\mathrm{Abl}^{[13,14]}$. GNF-2 binds to the myristate binding site of Abl, leading to changes in the structural dynamics of the ATPbinding site. Thus, therapeutically relevant inhibition of Bcr$\mathrm{Abl}$ activity can be achieved using inhibitors that bind to the myristate binding site and that combining allosteric and ATPcompetitive inhibitors may overcome resistance to either agent alone.

In an effort to find new inhibitors to overcome imatinib resistance, we used structure-based drug design and focused synthetic libraries of curcumin analogs, and identified C817 (3,5-bis(3-pyridinyl methylene)-4-piperidinone) as a potent novel inhibitor of $\mathrm{Abl}$ kinase. Biochemical kinase assays with purified WT and mutant recombinant Abl kinase fusion proteins demonstrated potent inhibition of Abl-catalyzed peptide substrate phosphorylation, including T315I mutation. In cellbased assays, the inhibitor effectively blocked proliferation of 32D cells expressing either WT Bcr-Abl or 3 of the most common imatinib mesylate-resistant Bcr-Abl variants observed in the clinical setting. Consistent with cell proliferation results, annexin $\mathrm{V}$ binding assays confirmed that $\mathrm{C} 817$ induced apoptosis of human leukemia blast K562 cells and imatinib-resistant K562/G01 cells via triggering mitochondrial pathway. Moreover, we demonstrated that C817 could inhibit the growth of leukemia progenitor/stem cells by colony forming units (CFU) and long term culture-initiating cells (LTC-IC) assay, which is one of the major reasons for leukemia recovery. In contrast, imatinib wasn't able to inhibit LTC-IC. Collectively, C817 is a promising compound for the treatment of patients with CML with Bcr-Abl kinase domain mutations that confer imatinib mesylate resistance.

\section{Materials and methods Reagents}

Imatinib was kindly provided by Novartis Pharma AG (Basel, Switzerland). A curcumin analogue, EF24, was discovered to be more active ${ }^{[15]}$ than its parent compound. To improve the solubility and activity further, we replace the 2-fluorinebenzyl group on EF24 with 3-pyridine to obtain the C817 molecule ${ }^{[16]}$ (Figure 1A). PathScan ${ }^{\circledR}$ Bcr/Abl Activity Assay (phosphoc-Abl, phospho-Stat5 and phospho-CrkL) Multiplex Western Detection and Apoptosis Antibody Sampler Kit (\#9915, caspase-3, cleaved caspase-3, caspase-9, cleaved caspase-9, caspase-7, cleaved caspase-7) were purchased from Cell Sig- naling Technology, Inc (Danvers, MA, USA). StemSpan ${ }^{\circledR}$ CC100, StemSpan ${ }^{\circledR}$ Serum-Free Expansion Medium (SFEM) , EasySep ${ }^{\circledR}$ Human Whole Blood CD34 Positive Selection Kit, MethoCult ${ }^{\circledR}$ GF H4434, and MyeloCult ${ }^{\circledR}$ H5100 were purchased from STEMCELL Technologies Inc (BC, Canada), Abl kinase substrate was purchased from Enzo Life Science, Inc (NY, USA). Recombinant wild type and mutant ABL kinases were purchased from Millipore Corporation (MA, USA).

\section{Cell culture}

32D, 32D-T315I, 32D-Q252H, and 32D-Y253F cell lines were constructed as described previously ${ }^{[17]}$. Human leukemic cells K562 were cultured and passaged in RPMI-1640 containing $10 \%$ heat-inactivated fetal bovine serum, $100 \mathrm{U} / \mathrm{mL}$ penicillin, $100 \mathrm{mg} / \mathrm{mL}$ streptomycin, and $2 \mathrm{mmol} / \mathrm{L}$ glutamine (medium A) in a $5 \%$ humidified $\mathrm{CO}_{2}$ atmosphere at $37^{\circ} \mathrm{C}$. Imatinib-resistant K562/G01 cell line was kindly provided by Prof Chun-zheng YANG (Institute of Hematology, Chinese Academy of Medical Sciences and Peking Union Medical College, Tianjin, China) ${ }^{[18]}$. K562/G01 cells were maintained in medium A containing or lacking $4 \mu \mathrm{mol} / \mathrm{L}$ imatinib. Logarithmically growing cells were exposed to the designated concentrations of C817. After these treatments, cells were pelleted and washed free of the drugs prior to the performance of the studies described below.

\section{Cell proliferation assays}

Exponentially growing cells were plated into 96-well plates at a final concentration of $5 \times 10^{4}$ cells $/ \mathrm{mL}$ and were incubated with or without C817 (from 0 to $30000 \mathrm{nmol} / \mathrm{L}$ ) for $48 \mathrm{~h}$. Cell proliferation was measured by using the 3-(4,5-dimethylthiazol-2-yl)-2,5-diphenyltetrazolium bromide (MTT; Sigma Chemical Company, St Louis, MO, USA) colorimetric dyereduction method. All experiments were repeated at least twice in triplicate. The drug concentration resulting in 50\% inhibition of the growth $\left(\mathrm{IC}_{50}\right)$ was determined.

\section{Tyrosine kinase assay}

The ABL kinase activity was tested using the Kinase-Glo Luminescent Kinase Assay Platform (Promega Corporation, WI, USA, Cat\# V6072), which provides a homogeneous, highthroughput screening method for measuring kinase activity by quantization the amount of ATP remaining in solution following a kinase reaction. The assays are performed in a single well of a multiwell plate by adding a volume of KinaseGlo Reagent equal to the volume of a completed kinase reaction and measuring luminescence. The luminescent signal is correlated with the amount of ATP present and is inversely correlated with the amount of kinase activity. Briefly, a 10 $\mu \mathrm{L}$ mixture containing $1 \mu \mathrm{L}$ of $\mathrm{C} 817(0.01,0.03,0.1,0.3$, or 0.9 $\mu \mathrm{mol} / \mathrm{L}), 3 \mu \mathrm{L}$ of $10 \mathrm{nmol} / \mathrm{L}$ Abl wild type or mutated kinase, $1 \mu \mathrm{L}$ of $(30 \mathrm{ng})$ Abl kinase substrate (EAIYAAPFAKKK) and $5 \mu \mathrm{L}$ of $\operatorname{ATP}(0.2$ or $2 \mu \mathrm{mol} / \mathrm{L})$ in kinase buffer [ $50 \mathrm{mmol} / \mathrm{L}$ HEPES (pH 7.3), $10 \mathrm{mmol} / \mathrm{L} \mathrm{MgCl}_{2}, 0.1 \% \mathrm{BSA}, 2 \mathrm{mmol} / \mathrm{L}$ DTT] was added to the wells, and the reactions were incubated for $20 \mathrm{~min}$ at $30^{\circ} \mathrm{C}$; the control wells did not contain C817. The 
reaction was stopped by addition of $10 \mu \mathrm{L}$ Kinase-Glo reagent, and the plate was read after a 10-min incubation time at RT on the Thermo Scientific Varioskan Flash in luminescence mode.

\section{Western blotting analysis of Bcr-Abl initiating signaling ${ }^{[19]}$}

Total protein extracts $(30 \mu \mathrm{g})$ were subjected to sodium dodecylsulfate-polyacrylamide gel electrophoresis (SDSPAGE). After electrophoresis, proteins were transferred to PVDF membrane $\left(150 \mathrm{~mA} ; 4^{\circ} \mathrm{C}\right)$ for $1.5 \mathrm{~h}$. The blots were blocked in blocking-buffer (1\% BSA, Tris- $\mathrm{HCl} 20 \mathrm{mmol} / \mathrm{L}$, $\mathrm{pH} 7.5, \mathrm{NaCl} 150 \mathrm{mmol} / \mathrm{L}, 0.05 \%$ Tween-20) for $1 \mathrm{~h}$ at room temperature and was followed by incubation with primary Abs (anti-phospho-Bcr-Abl, phospho-STAT5, or phosphoCrkL antibody) overnight at $4{ }^{\circ} \mathrm{C}$ and then with anti-rabbit peroxidase-conjugated secondary IgG antibodies and developed with enhanced chemiluminescence (ECL) substrate, then the bands on membrane were scanned by Carestream Image Station System.

\section{Apoptosis and cell cycle assessment by flow cytometry}

After drug treatments, cells were resuspended in $100 \mu \mathrm{L}$ of staining solution containing Annexin-V-FITC/PI in a HEPES buffer [10 mmol/L HEPES (pH 7.4), $150 \mathrm{mmol} / \mathrm{L} \mathrm{NaCl}, 5$ $\mathrm{mmol} / \mathrm{L} \mathrm{KCl}, 1 \mathrm{mmol} / \mathrm{L} \mathrm{MgCl}_{2}$, and $2 \mathrm{mmol} / \mathrm{L} \mathrm{CaCl}_{2}$ in Annexin-V-FITC/PI double staining kit (KeyGEN Biotech, Nanjing, China) according to the manufacturer's protocol. After incubation at room temperature for 15 min in the dark, cells were analyzed using flow cytometer (BD FACSCanto II). Annexin $\mathrm{V}$ binds to those cells that express phosphatidylserine on the outer layer of the cell membrane. Cells that stain positively for annexin $\mathrm{V}$ are scored as apoptotic cells.

K562 and K562/G01 cells were cultured in the presence of C817 at the indicated concentration for $24 \mathrm{~h}$, harvested, and then stained with PI and subsequently analyzed by flow cytometry, with quantitation using FlowJo software.

\section{JC-1 mitochondrial membrane potential (MMP) assay}

After drug treatments, cells were resuspended in staining solution in JC-1 Mitochondrial Membrane Potential Assay Kit (KeyGEN Biotech, Nanjing, China) according to the manufacturer's protocol. After incubation at room temperature for 10 min in the dark, cells were analyzed using flow cytometer.

\section{Colony-forming units assays}

Bone marrow samples were obtained with informed consent from patients with CML and from patients with non-myeloid hematologic disorders (eg, iron deficiency and thrombocytopenia). CD34 ${ }^{+}$cells were enriched by EasySep ${ }^{\circledR}$ Human Whole Blood CD34 Positive Selection Kit. CD34 ${ }^{+}$cells, cultured for $24 \mathrm{~h}$ alone or in the presence of C817, were plated in Metho$\mathrm{Cult}^{\circledR}$ GF H4434 medium for 10-14 d and assessed for the presence of colony-forming units (CFU).

Long term culture-initiating cells (LTC-ICs) assay ${ }^{[20-23]}$ M2-10B4 cells and SL/SL fibroblasts were established as feeder layers then irradiated at $60 \mathrm{~Gy}$. MNC cells from CML bone marrow were treated with or without $\mathrm{C} 817$, or imatinib for $24 \mathrm{~h}$, and then plated in quinplicate on the irradiated feeder layers in MyeloCult ${ }^{\circledR}$ H5100 medium supplemented with hydrocortisone at a final concentration of $1 \mu \mathrm{mol} / \mathrm{L}$. Cultures were maintained for 5 weeks with weekly half medium changes. After 5 weeks, cobblestone area forming cells (CAFC) were counted.

\section{Statistical analysis}

Group differences were examined by unpaired Student $t$ test. Differences were considered significant at $P<0.05$. All of these analyses were done using SPSS (Statistical Package for the Social Sciences) Software.

\section{Results}

C817 inhibits the growth of imatinib-sensitive and -resistant cells expressing wild-type or mutation of Bcr-Abl

Mutations of the $\mathrm{Bcr}-\mathrm{Abl}$ or overexpression of $\mathrm{Bcr}-\mathrm{Abl}$ made $\mathrm{Bcr}-\mathrm{Abl}$ tyrosine kinase insensitive to imatinib. The frequently observed imatinib mesylate-resistant Bcr-Abl mutants include Q252H, Y253F, E255K, M351T, H396P, and T315I, etc ${ }^{[2,3]}$. As expected, 32D cells harboring T315I, Q252H, and Y253F site mutant of ABL kinase has somewhat resistance to imatinb compared to 32D cells transfected with WT Bcr-Abl (Figure 1B). In contrast, $\mathrm{IC}_{50}$ value of $\mathrm{C} 817$ to $32 \mathrm{D}$ cells harboring $\mathrm{WT}$, T315I, Q252H, and Y253F site mutant of Bcr-Abl kinase has no significant difference (Figure $1 \mathrm{C}$ and Table 1).

Table 1. IC $\mathrm{C}_{50}$ value of $\mathrm{C} 817$ to $32 \mathrm{D}$ cells harboring different site mutant of $\mathrm{ABL}$ kinase or over-expressing wild-type Bcr-Abl.

\begin{tabular}{lcc}
\hline & C817 $(\mu \mathrm{mol} / \mathrm{L})$ & Imatinib $(\mu \mathrm{mol} / \mathrm{L})$ \\
\hline 32D-WT & $0.67 \pm 0.06$ & $0.13 \pm 0.04$ \\
32D-T315I & $3.32 \pm 0.14$ & $22.22 \pm 1.98$ \\
32D-Q252H & $0.50 \pm 0.12$ & $2.26 \pm 0.97$ \\
32D-Y253F & $0.56 \pm 0.18$ & $2.03 \pm 0.67$ \\
K562 & $0.88 \pm 0.23$ & $0.20 \pm 0.07$ \\
K562/G01 & $0.44 \pm 0.15$ & $7.21 \pm 1.21$ \\
\hline
\end{tabular}

Resistance cell line K562/G01 was generated by culturing K562 cells in gradually increased concentrations of imatinib over a period of several months, which was established with more than 30 fold resistance to imatinib as compared with that of parental sensitive cell line (Figure $1 \mathrm{E})^{[18]}$. The amplification of $B c r-A b l$ gene was observed by FISH staining (Figure 1D).

Treatment of continuously proliferating leukemia cells with varying concentrations of C817 for indicated length of time decreased the number of viable cells detected by MTT assays (Figure 1F). When K562 or K562/G01 cells were exposed to C817 at concentrations for $48 \mathrm{~h}$, clear inhibition of cell growth in a concentration-dependent manner was observed (Figure $1 F)$. Additionally, there is no significantly different sensitivity to $\mathrm{C} 817$ between imatinib sensitive and resistant cell lines. The 
A<smiles>O=C1/C(=C/c2ccncc2)CNC/C1=C\c1cccnc1</smiles>

3,5-bis(3-pyridinyl methylene)-4-piperidinone (Molecular weight 277)

D

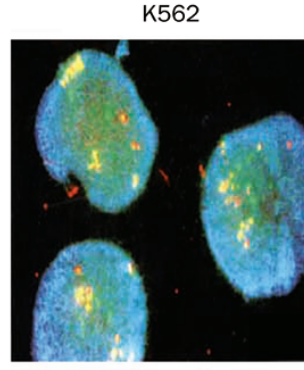

K562/G01

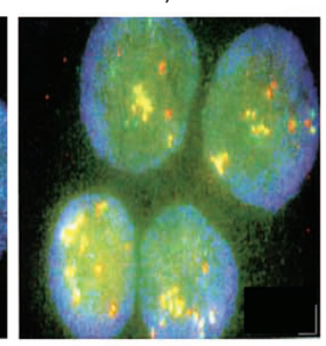

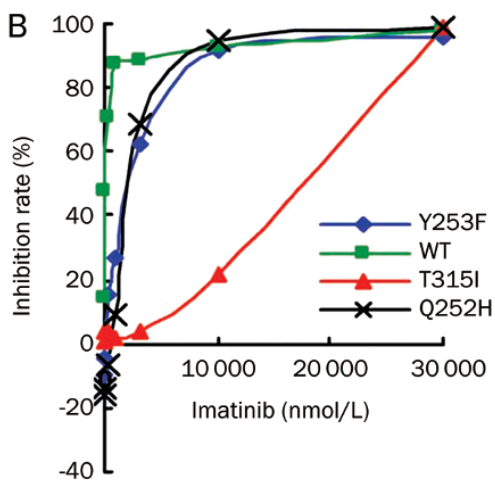

$\mathrm{E}$

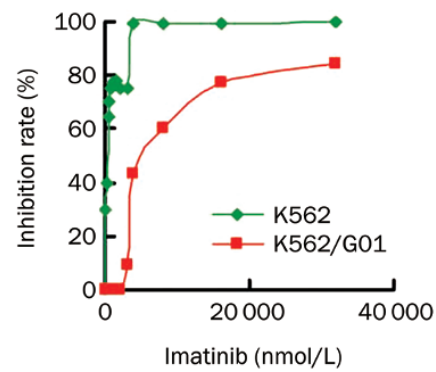

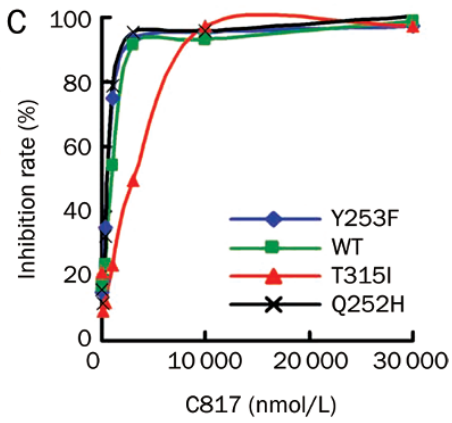

$\mathrm{F}$

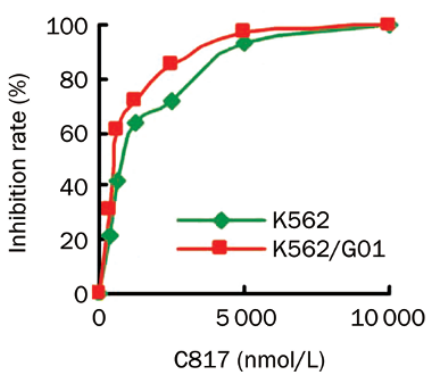

Figure 1. C817 inhibits proliferation of imatinib-resistant $\mathrm{CML}$ cells overexpressing wild-type or mutant Bcr-Abl. (A) Chemical structure of C817. (B, C) Proliferation of 32D, 32D-T315I, 32D-Q252H, and 32D-Y253F cell lines in the presence of escalating concentrations of (B) imatinib mesylate (0-30 000 $\mathrm{nmol} / \mathrm{L}$ ) or (C) C817 (0-30000 nmol/L). Cell growth was assessed by MTT-based viability assay. (D) Bcr-abl gene copies analyzed by FISH in K562 or K562/G01 cells. (E, F) Proliferation of K562 or K562/G01 cells in the presence of escalating concentrations of (E) imatinib mesylate (0-32 000 nmol/L) or (F) C817 (0-10000 nmol/L). Cell growth was assessed by MTT-based viability assay.

$\mathrm{IC}_{50}$ values of $\mathrm{K} 562$ and $\mathrm{K} 562 / \mathrm{G} 01$ cell lines were $0.88 \mu \mathrm{mol} / \mathrm{L}$ and $0.44 \mu \mathrm{mol} / \mathrm{L}$, respectively.

Our results demonstrated C 817 was able to inhibit the growth of imatinib resistant cells resulted from either $\mathrm{Bcr}-\mathrm{Abl}$ gene amplication or site mutant of ABL kinase.

\section{C817 inhibits wild-type and domain mutant $A B L$ kinase activity} in vitro

To explore the relationship between the effect of C817 on the ABL kinase activity and leukemia cell growth inhibition directly, biochemical mechanism in vitro kinase assay was performed. Ten nanograms of recombinant Abl kinase proteins were mixed with different concentrations of C817, and kinase assays were performed as described in Materials and methods by using various concentrations of ATP. The values from individual samples were analyzed and plotted as a function of drug concentration. All Abl kinase proteins were efficiently inhibited (Figure 2A-2D and Table 2). In this assay, the cata-

Table 2. $\mathrm{IC}_{50}(\mathrm{nmol} / \mathrm{L})$ value for $\mathrm{C} 817$ on $\mathrm{ABL}$ kinase activity in vitro.

\begin{tabular}{lcccc}
\hline & ABL-WT & ABL-T315I & ABL-Q252H & ABL-Y253F \\
\hline ATP 0.2 $\mu \mathrm{mol} / \mathrm{L}$ & $12.32 \pm 4.11$ & $3.74 \pm 1.22$ & $7.17 \pm 1.65$ & $21.32 \pm 2.36$ \\
ATP $2 \mu \mathrm{mol} / \mathrm{L}$ & $10.56 \pm 3.34$ & $8.67 \pm 2.42$ & $8.76 \pm 1.87$ & $41.84 \pm 5.67$ \\
\hline
\end{tabular}

lytic activity of ABL-T315I was inhibited in the same concentration range as the other Abl mutants and Abl WT with $\mathrm{IC}_{50}$ of $3.74 \mathrm{nmol} / \mathrm{L}$ when ATP was $0.2 \mu \mathrm{mol} / \mathrm{L}$. Moreover, these analyses showed that the $\mathrm{IC}_{50}$ values remained in the same range in the presence of increasing ATP concentrations $(2 \mu \mathrm{mol} / \mathrm{L})$, suggesting that C817 is not an ATP-competitive inhibitor.

Exposure of K562 cells to C817 inhibits tyrosine phosphorylation of Bcr-Abl and its downstream targets STAT5 and CrkL

To further establish a direct link between the pronounced cellular effects of C817 and inhibition of Bcr-Abl tyrosine kinase activity, we examined the tyrosine phosphorylation status (Tyr245) of Bcr-Abl and downstream substrates STAT5 and CrkL. Specifically, immunoblot analysis of lysates from C817-treated cells with antiphospho-STAT5 (Tyr694) and antiphospho-CrkL (Tyr207) monoclonal antibodies revealed a concentration-dependent reduction in phosphorylation of these Bcr-Abl targets (Figure 2E). Bcr-Abl tyrosine phosphorylation levels were simultaneously monitored and found to be drastically reduced at a concentration of $1 \mu \mathrm{mol} / \mathrm{L} \mathrm{C817}$ in both K562 and K562/G01 cells (Figure 2E). Together, these data establish that C817-mediated effects on proliferation of CML cells correlate with a dramatic reduction in Bcr-Abl kinase activity. 
A
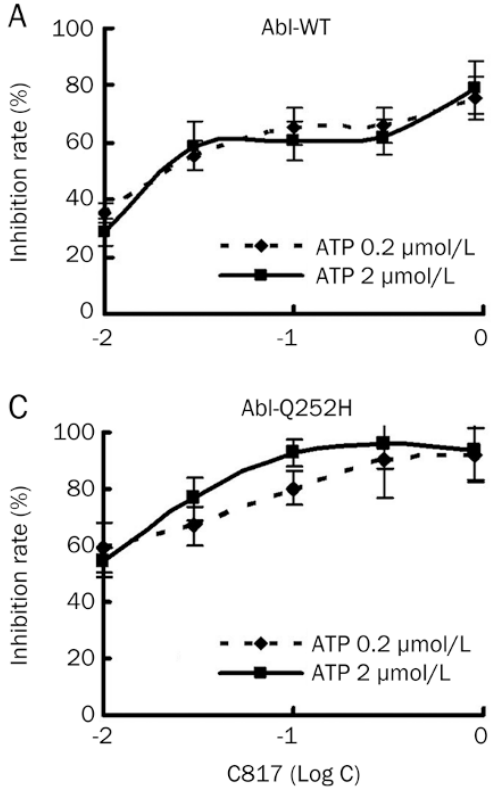

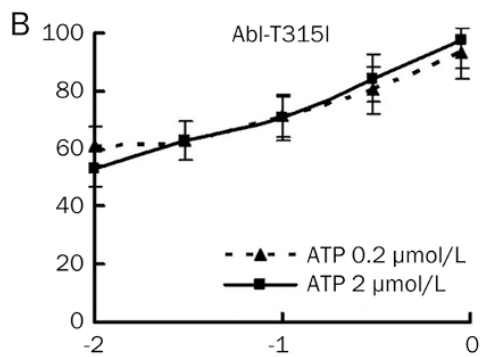

D

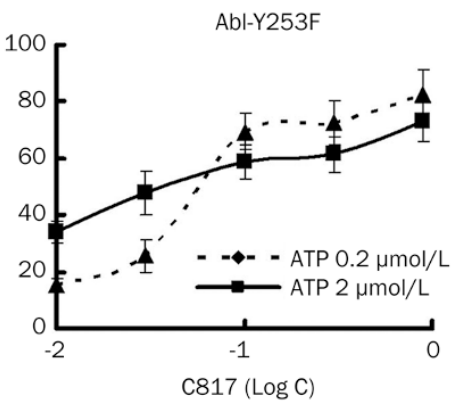

E

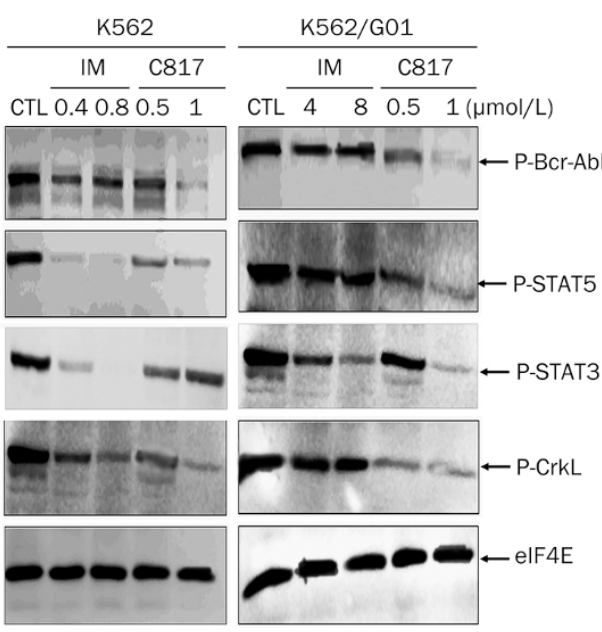

Figure 2. C817 inhibits wild-type or mutant Abl kinase in vitro or Bcr-Abl initiating signaling in imatinib-resistant cells. (A-D) Wild-type or T315I/ Q252H/Y253F mutant Abl kinase assays were performed at different ATP concentration as described in Materials and methods by using KinaseGlo Luminescent Kinase Assay Platform. (E) C817 inhibits tyrosine phosphorylation of Bcr-Abl and downstream targets STAT-5 and CrkL. K562 or K562/G01 cells $\left(1 \times 10^{6}\right)$ were incubated for $24 \mathrm{~h}$ in $20 \mathrm{~mL}$ media in the presence of C817 $(0,0.5$, or $1 \mu \mathrm{mol} / \mathrm{L})$. Total cell lysates were prepared and separated by SDS-PAGE on $10 \%$ gels (30 $\mathrm{\mu g}$ protein/lane). Western blotting analysis for phospho-Bcr-Abl, phospho-STAT5, phospho-CrkL, and elF4E (protein loading control) was performed by using a Pathscan Bcr/Abl Multiplex Western Detection Kit (Cell Signaling Technology).

C817 induces the apoptosis of imatinib-sensitive and -resistant CML cells through triggering mitochondrial pathway

To clarify whether the growth inhibition of imatinib-sensitive and -resistant leukemic cells by C817 is associated with induction of apoptosis, we used Annexin V-FITC/PI staining for confirmation and quantification of C817-induced apoptosis in K562 and K562/G01 cells. Cells were cultured for $24 \mathrm{~h}$ in the presence of $\mathrm{C} 817(0.5$ and $1 \mu \mathrm{mol} / \mathrm{L})$. The percentages of apoptotic cells were then assessed by annexin V-FITC/ PI staining and flow cytometry. In agreement with cellular proliferation assay results, apoptosis was induced in a concentration-dependent manner in both imatinib-sensitive and -resistant K562 cells (Figure 3).

The mitochondrial pathway of apoptosis functions in response to various types of stress. A variety of chemotherapeutic agents trigger apoptosis in susceptible cells by inducing MMP disruption, followed by release of cytochrome $c$, which interacts with the cytosolic docking protein, thereby facilitating activation of procaspase- 9 and subsequent proteolytic processing of procaspase- 3 and procaspase- $7^{[24-26]}$. Once activated, these caspases cleave and activate downstream effector caspases (including 3,6, and 7), which in turn cleave cytoskeletal and nuclear proteins like PARP, DFF and lamin A, and induce apoptosis. MMP is an important parameter of mitochondrial function used as an indicator of cell health. JC-1 can selectively enter into mitochondria and reversibly change color from green to red as the MMP increases in healthy cells. On the other hand, in apoptotic or unhealthy cells with low MMP, JC-1 remains in the monomeric form, which shows only green fluorescence. The ratio of Red/Green represents the amount of healthy cells ${ }^{[27]}$.

These experiments demonstrated that treatment with C817 significantly led to reduction of MMP, which resulted in Green color of JC-1 increasing, while Red color of JC-1 decreasing (Figure 4A). Thus, the ratio of Red/Green decreased dramatically after C817 treatment. The alteration of MMP promoted the release of cytochrome $c$, which in turn cleaved procaspases 9, 7, and 3 to activating caspases 9, 7, and 3 (Figure 4B), which finally cleaved nuclear proteins PARP, and induced apoptosis.

In addition, C817 arrested the cell cycle at the $G_{2} / M$ phase in both K562 and K562/G01 cells (Figure 3B).

C817 eradicates human leukemia progenitor/stem cells potently To determine whether these events could be extended to primary leukemia progenitor/stem cells from patients, and whether C817 is more sensitive to leukemia progenitor/stem cells from CML patients than from healthy donors, CD $34^{+}$ cells were isolated, then growth inhibitory effects were tested by CFU and LTC-IC assay. It is significant that, treatment with C817 $0.25,0.5$, or $1 \mu \mathrm{mol} / \mathrm{L}$ resulted in a marked suppression of leukemia progenitor cells from CML patients by $42.8 \%, 71.2 \%$, or $88.4 \%$, respectively, in colony formation of CD34 ${ }^{+}$CML cells (Figure 5A), and a little moderate suppression of progenitor cells from healthy donors by $12.8 \%, 31.7 \%$, or $42.4 \%$, respectively. These results demonstrated that C817 exerted relatively little toxicity toward normal bone marrow progenitor cells. Given that C817 can potently inhibit imatinib resistant K562/G01 cells, they might also kill progenitor cells 

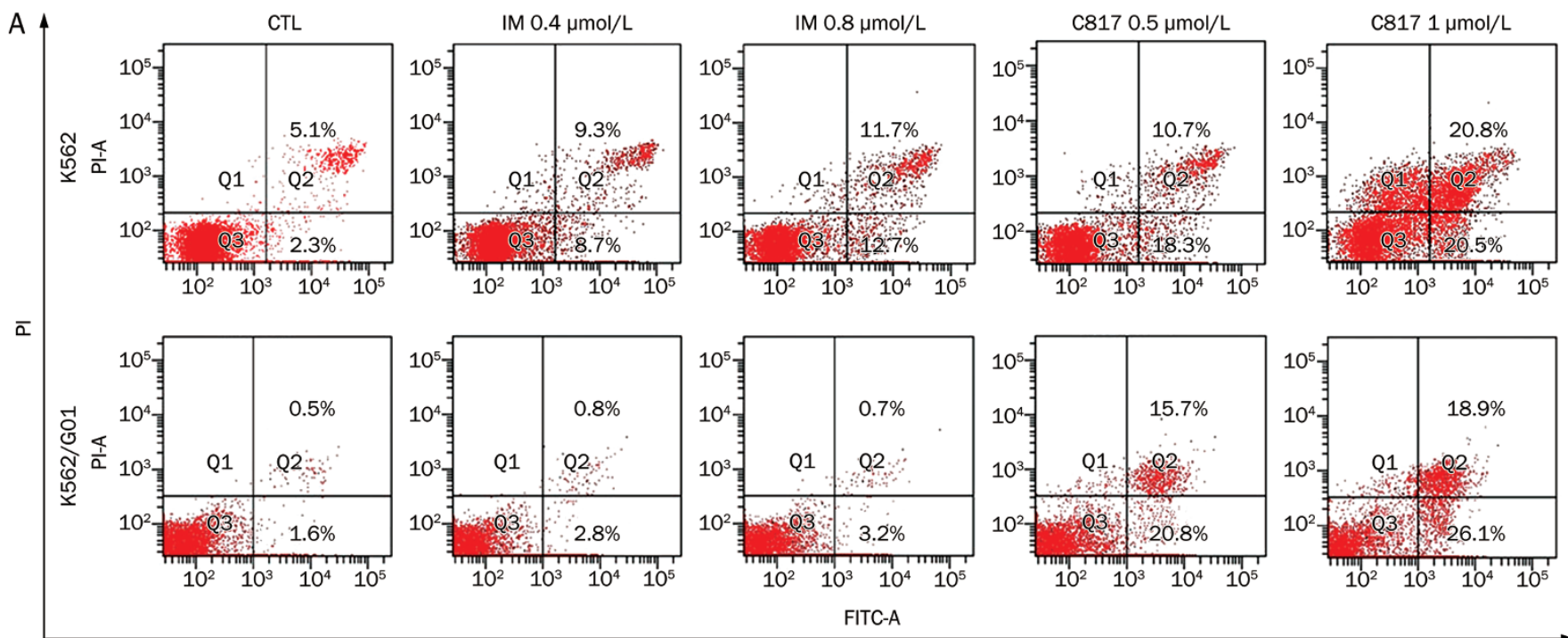

Annexin-FITC

B
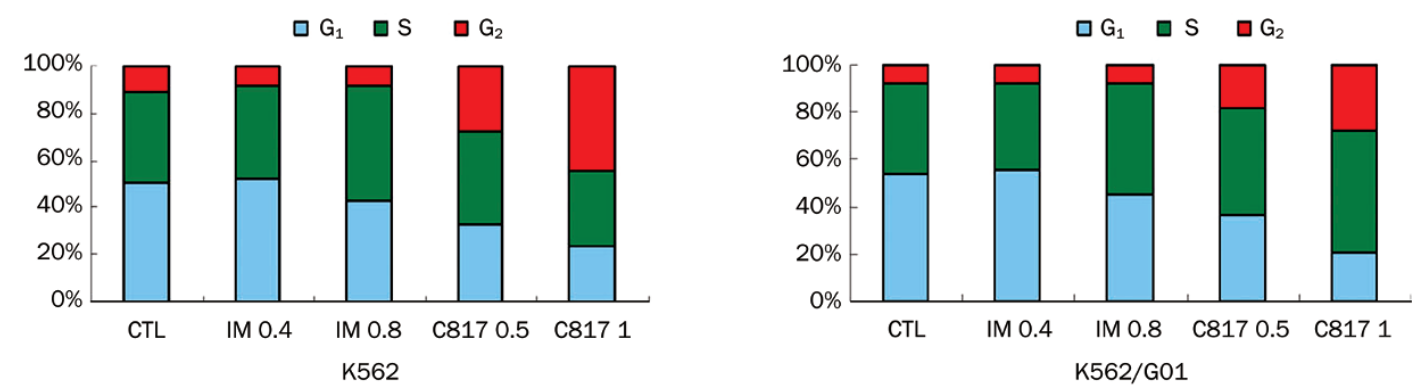

Figure 3. Effect of C817 on induction of apoptosis and cell cycle arrest in imatinib-sensitive or -resistant CML cells. (A) K562 and K562/G01 cells were cultured in the presence of $\mathrm{C} 817$ at indicated concentrations for $24 \mathrm{~h}$, harvested, then dually stained with annexin $\mathrm{V}$ and PI and subsequently analyzed by flow cytometry. (B) $\mathrm{C} 817$ arrests the cell cycle at the $\mathrm{G}_{2}$ phase in both imatinib-sensitive and -resistant $\mathrm{CML}$ cells. K562 and K562/G01 cells were cultured in the presence of $\mathrm{C} 817$ at the indicated concentrations for $24 \mathrm{~h}$, harvested, and then stained with PI and subsequently analyzed by flow cytometry, with quantitation using FlowJo software.

isolated from bone marrow of imatinib resistant CML patient. The results of CFU assay demonstrated that C817 were able to suppress the growth of $\mathrm{CFU}$ from imatinib resistant patient efficiently (Figure 5B). Hence primary CML progenitor cells from both imatinib sensitive and resistant patients, like other leukemia cells, were sensitive to C817. Further on, C817 has somewhat selectivity between normal and CML progenitor cells.

Another important mechanism of imatinib resistance is leukemia stem cells accumulation in imatinib therapy patients ${ }^{[4,5]}$. Thus, we investigated the effects of C817 on CML stem cells and compared these effects with those of imatinib by testing LTC-ICs, which represent primitive stem cells. CML MNCs (mononuclear cells) were exposed to C817 or imatinib for $24 \mathrm{~h}$. After drug exposure, the cells were washed to remove the drug, and assays for primitive (LTC-ICs) stem cells were performed in the absence of further drug exposure. The effects of C817 and imatinib on CML LTC-ICs are depicted in Figure 5C. Unexpectedly, imatinib stimulated the self-renew of LTCICs in two of three samples from CML patient bone marrow. In consistent with several reports that human CML leukemia stem cells are insensitive to imatinib despite inhibition of BCR-ABL activity ${ }^{[4,5]}$. In contrast, exposure to C817 for $24 \mathrm{~h}$ resulted in a significant inhibition of CML LTC-ICs growth (up to $70 \%$, at $1 \mu \mathrm{mol} / \mathrm{L}$ ) compared with imatinib. These results indicated that C817 would eradicate CML leukemia stem cells efficiently.

\section{Discussion}

The most common resistance mechanism of imatinib involves the acquisition of mutations in the ATP-binding site that prevent drug binding or that increase the affinity for ATP, including $\mathrm{Q} 252 \mathrm{H}, \mathrm{Y} 253 \mathrm{~F}$, and T315I, and so on ${ }^{[2,3]}$. Among the Bcr$\mathrm{Abl}$ point mutations, the T315I mutation is most difficult to overcome and is resistant to the three Bcr-Abl inhibitors that are currently approved for the treatment of CML: imatinib, nilotinib and dasatinib ${ }^{[11,12]}$. Thus novel agents capable of inhibiting the tyrosine kinase activity, regardless of its wildtype or mutant status, are likely to be highly effective against advanced stages of CML. Resistance to ATP-competitive kinase inhibitors limits the duration of response that can be achieved with this class of therapeutics. Thus, it is urgent to 

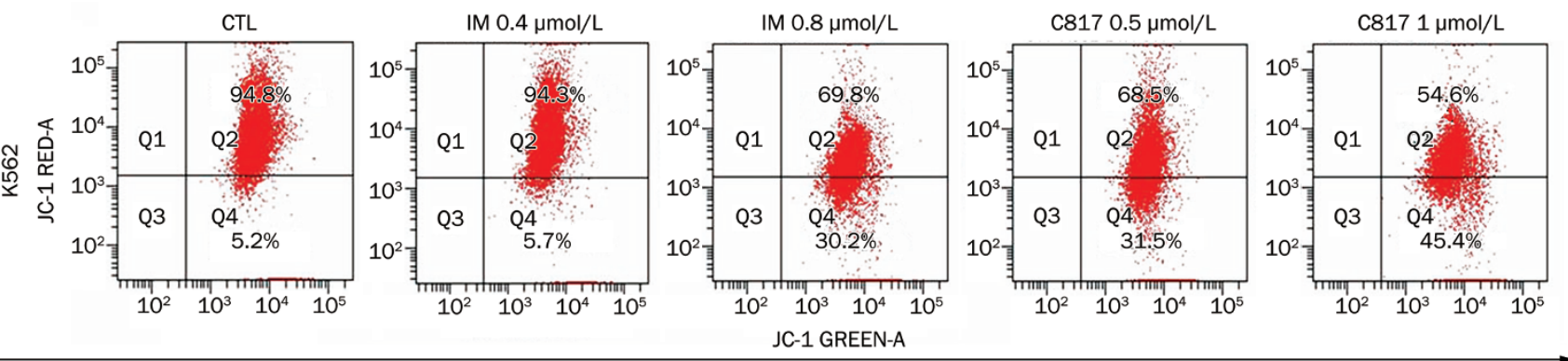

JC-1 green

B

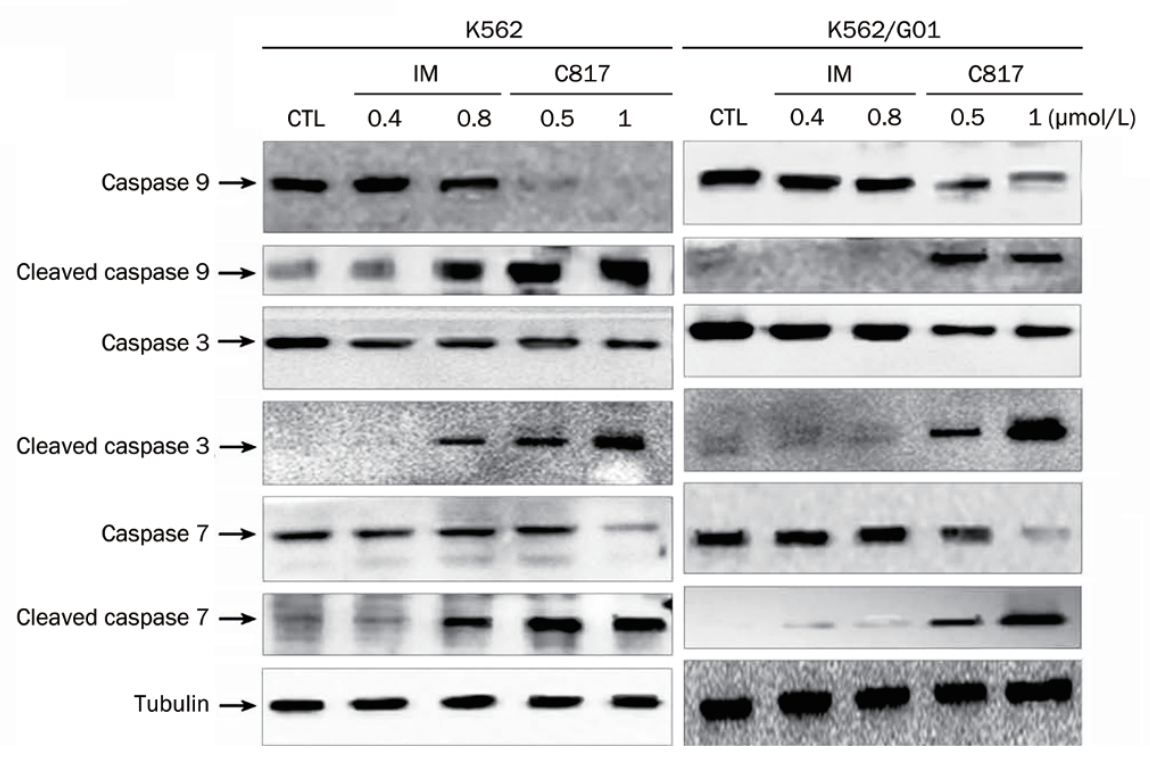

Figure 4. C817 triggers mitochondrial pathway of apoptosis in imatinib-sensitive or -resistant CML cells. (A) Treatment of K562 or K562/G01 cells with C817 at indicated concentrations for $24 \mathrm{~h}$ significantly led to reduction of MMP examined by JC-1 staining. (B) Treatment of imatinib-sensitive or -resistant K562 cells with C817 for $24 \mathrm{~h}$ activated the stream of caspase 9, 7, and 3 pathway analyzed by Western blotting. Tubulin serves as a control for the loading of protein levels.

develop novel kinase inhibitor distinct from canonical ATPcompetitive inhibitors.

To achieve this goal, some small molecule compounds have been designed to target $\mathrm{Bcr}-\mathrm{Abl}$ motifs remote from the kinase domain. The activity of these drugs remains unaffected by the presence of mutations in the kinase domain of the enzyme, including ON012380, GNF-2, and GNF-5 ${ }^{[13,14,28-31]}$. GNF-5, an analog of GNF-2 having improved pharmacokinetic properties, when combined with the ATP-competitive inhibitors imatinib or, can suppressed the emergence of resistance mutations in vitro, displayed inhibitory activity against $\mathrm{T} 315 \mathrm{I} \mathrm{Bcr}-\mathrm{Abl}$ and displayed in vivo efficacy against the recalcitrant T315I Bcr-Abl mutant in a murine bone-marrow transplantation model.

Current study demonstrated that C817 has capacity of inhibiting imatinib-resistant cells, including Abl mutation and $\mathrm{Bcr}-\mathrm{Abl}$ gene overexpression cells. The kinase activity assay in vitro unveiled that $\mathrm{C} 817$ could inhibit $\mathrm{Abl}$ kinase activity, either wild type or site mutations in Q252H, Y253F, and T315I. Further on, this suppression of $\mathrm{C} 817$ to $\mathrm{Abl}$ kinase was in a non-ATP competitive manner. The effects of $\mathrm{C} 817$ on Bcr-Abl kinase activity in imatinib-sensitive or -resistant cells was con- sistent with kinase assay in vitro.

Besides mutation of Abl kinase attributing to imatinib resistance, the accumulation of LSCs play critical role in CML relapse after imatinib therapy ${ }^{[4,5]}$. There are three potential origins of LSCs: (i) normal hematopoietic stem cells that can mutate to leukemia stem cells; (ii) leukemia committed progenitors that can dedifferentiate to become leukemia stem cells; and (iii) LSCs could also result from a differentiated mature leukemia cells that reacquire the stem cell capability for self-renewal ${ }^{[32,33]}$. Thus, the only way to cure leukemia is to eradicate differentiated mature leukemia cells, leukemia progenitors, and LSCs simultaneously.

LTC-IC is recognized as the most stringent assay to detect very primitive human hematopoietic stem cells in vitro ${ }^{[20-23]}$. For successful read-out, stem cells must be fully functional, survive for 5 weeks in the presence of a stromal layer. Compared with control, LTC-ICs were accumulated in the imatinib group, indicating that imatinib exert a protective effect on CML stem/progenitor cells in these culture conditions. This result is consistent with several reports that human CML leukemia stem cells are insensitive to imatinib despite inhibi- 

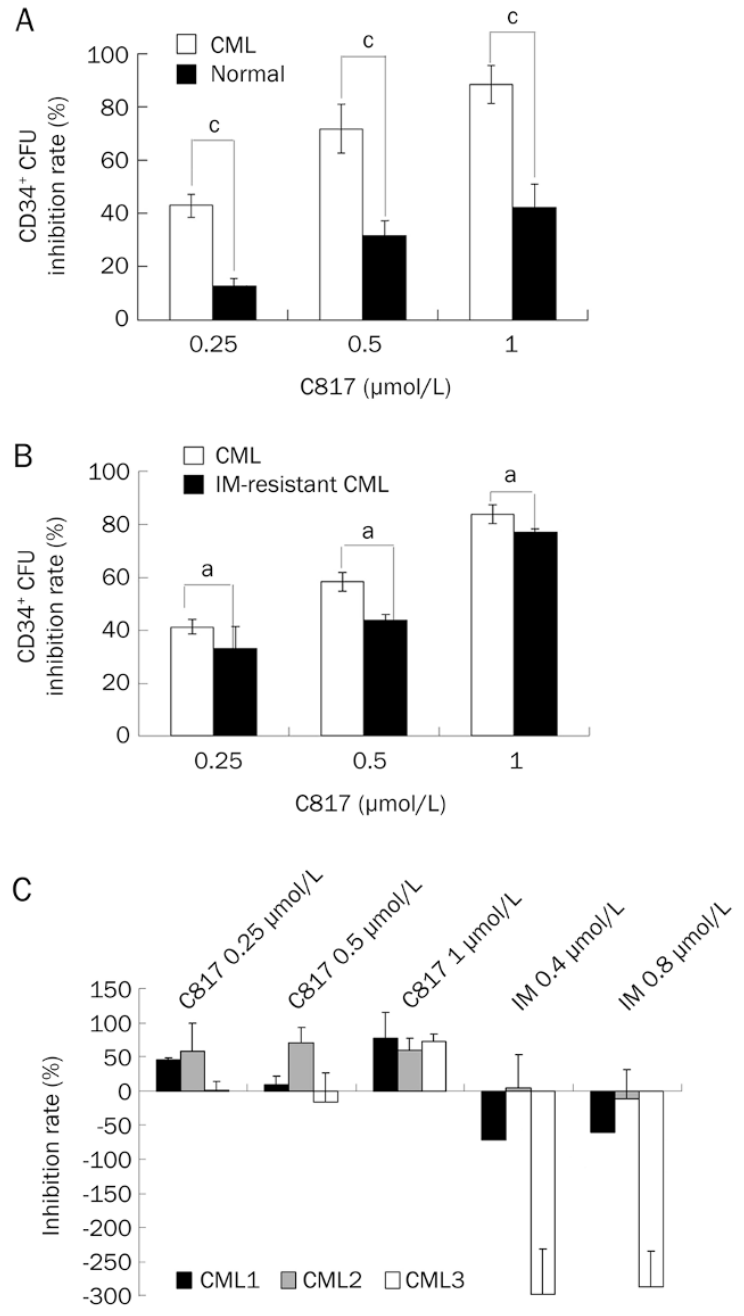

Figure 5. Effects of $\mathrm{C} 817$ on $\mathrm{CML}$ progenitor/stem cells survival from human bone marrow. (A) Colony formation of CML CD34 ${ }^{+}$cells. CML $(n=3)$ or normal $\mathrm{CD} 34^{+}$cells were isolated and cultured with low growth factors, either without inhibitors (control), or in the presence of graded concentrations of $\mathrm{C} 817$ for $24 \mathrm{~h}$ and then plated in methylcellulose progenitor culture for $14 \mathrm{~d}$. Data are presented as the percentage of suppression of CFUs of $\mathrm{CML}$ or normal $\mathrm{CD} 34^{+}$cells compared to untreated controls. Significant differences between $\mathrm{CML}$ and normal $\mathrm{CD} 34^{+}$cells (unpaired $t$ tests; ${ }^{c} P<0.01$ ) are indicated. (B) Colony formation of imatinibresistant $\mathrm{CML} \mathrm{CD} 34^{+}$cells. Data are presented as the percentage of suppression of CFUs compared to untreated controls. No significant differences between $\mathrm{CML}$ and imatinib-resistant $\mathrm{CML} \mathrm{CD} 34^{+}$cells (unpaired $t$ tests; ${ }^{a} P>0.05$ ) are indicated. (C) Effects of C817 on LTC-IC cells self-renew from $\mathrm{CML}$ bone marrow. MNCs from $\mathrm{CML}$ patients were exposed to $\mathrm{C} 817$ at the concentrations indicated for $24 \mathrm{~h}$. Cells were then assayed for primitive progenitors (LTC-IC) by counting CAFC. The percentage inhibition of primitive progenitor growth after $\mathrm{C} 817$ or imatinib treatment relative to untreated controls is shown. Results represent the mean plus or minus SEM based on quinplicate wells $(\mathrm{CML}, n=3)$. Error bars represent SEM.

tion of BCR-ABL activity. In contrast, the addition of C817 10 $\mu \mathrm{mol} / \mathrm{L}$ significantly reduced LTC-IC compared with no drug control.
In conclusion, we identified C817 as a potent inhibitor of Abl kinases in vitro and ex vivo. In cell-based assays, C817 effectively blocked proliferation of 32D cells expressing either WT $\mathrm{Bcr}-\mathrm{Abl}$ or 3 of the most common imatinib-resistant Bcr-Abl variants. Moreover, C817 could inhibit the growth of leukemia progenitor/stem cells. Collectively, C817 is a promising compound for the treatment of patients with CML with BcrAbl kinase domain mutations that confer imatinib resistance.

\section{Acknowledgements}

We gratefully acknowledge the National Natural Science Foundation of China (30901824, 81173096, 81273541, 30873101, and 30472187), National Science and Technology Foundation of China for Key Projects of "Major New Drugs Innovation and Development" (2012ZX09103-101-028), the Natural Science Foundation of Fujian Province of China (Outstanding Project 2011J06013), and the Educational Bureau of Fujian Province of China (JA11101) for this project.

\section{References}

1 Druker BJ, Talpaz M, Resta DJ, Peng B, Buchdunger E, Ford JM, et al. Efficacy and safety of a specific inhibitor of the BCR-ABL tyrosine kinase in chronic myeloid leukemia. N Engl J Med 2001; 344: 10317.

2 Gorre ME, Mohammed M, Ellwood K, Hsu N, Paquette R, Rao PN, et al. Clinical resistance to STI-571 cancer therapy caused by BCR-ABL gene mutation or amplification. Science 2001; 293: 876-80.

3 von Bubnoff N, Schneller F, Peschel C, Duyster J. BCR-ABL gene mutations in relation to clinical resistance of Philadelphiachromosome-positive leukaemia to STI571: a prospective study. Lancet 2002; 359: 487-91.

4 Perl A, Carroll M. BCR-ABL kinase is dead; long live the CML stem cell. J Clin Invest 2011; 121: 22-5.

5 Corbin AS, Agarwal A, Loriaux M, Cortes J, Deininger MW, Druker BJ. Human chronic myeloid leukemia stem cells are insensitive to imatinib despite inhibition of BCR-ABL activity. J Clin Invest 2011; 121: 396-409.

6 Larson RA, Hochhaus A, Hughes TP, Clark RE, Etienne G, Kim DW, et al. Nilotinib vs imatinib in patients with newly diagnosed Philadelphia chromosome-positive chronic myeloid leukemia in chronic phase: ENESTnd 3-year follow-up. Leukemia 2012; 26: 2197-203.

7 Saglio G, Kim DW, Issaragrisil S, Coutre P, Etienne G, Lobo C, et al. Nilotinib versus imatinib for newly diagnosed chronic myeloid leukemia. N Engl J Med 2010; 362: 2251-9.

8 Rosti G, Palandri F, Castagnetti F, Breccia M, Levato L, Gugliotta G, et al. Nilotinib for the frontline treatment of $\mathrm{Ph}(+)$ chronic myeloid leukemia. Blood 2009; 114: 4933-8.

9 O'Hare T, Walters DK, Stoffregen EP, Jia T, Manley PW, Mestan J, et al. In vitro activity of Bcr-Abl inhibitors AMN107 and BMS-354825 against clinically relevant imatinib-resistant $A b l$ kinase domain mutants. Cancer Res 2005; 65: 4500-5.

10 Weisberg E, Manley PW, Breitenstein W, Bruggen J, Cowan-Jacob SW, Ray A, et al. Characterization of AMN107, a selective inhibitor of native and mutant Bcr-Abl. Cancer Cell 2005; 7: 129-41.

11 Redaelli S, Piazza R, Rostagno R, Magistroni V, Perini P, Marega M, et al. Activity of bosutinib, dasatinib, and nilotinib against 18 imatinibresistant BCR/ABL mutants. J Clin Oncol 2009; 27: 469-71.

12 Cortes JE, Kantarjian H, Shah NP, Bixby D, Mauro MJ, Flinn I, et al. Ponatinib in refractory Philadelphia chromosome-positive leukemias. 
N Engl J Med 2012; 367: 2075-88.

13 Adrián FJ, Ding Q, Sim T, Velentza A, Sloan C, Liu Y, et al. Allosteric inhibitors of Bcr-abl-dependent cell proliferation. Nat Chem Biol 2006; 2: 95-102.

14 Zhang J, Adrián FJ, Jahnke W, Cowan-Jacob SW, Li AG, lacob RE, et al. Targeting Bcr-Abl by combining allosteric with ATP-binding-site inhibitors. Nature 2010; 463: 501-6.

15 Adams BK, Ferstl EM, Davis MC, Herold M, Kurtkaya S, Camalier RF, et al. Synthesis and biological evaluation of novel curcumin analogs as anti-cancer and anti-angiogenesis agents. Bioorg Med Chem 2004; 12: 3871-83.

16 Liu Y, Xu JH, Li N, Zhang NW, Xu JH. Synthesis of 3,5-dibenzylidenepiperidin-4-one analogs and their antitumor activities in vitro. Chin J Med Chem 2011; 21: 262-6.

17 Luo H, Quan H, Xie C, Xu Y, Fu L, Lou L. HH-GV-678, a novel selective inhibitor of Bcr-Abl, outperforms imatinib and effectively overrides imatinib resistance. Leukemia 2010; 24: 1807-9.

18 Qi J, Peng H, Gu ZL, Liang ZQ, Yang CZ. Establishment of an imatinib resistant cell line K562/G01 and its characterization. Zhonghua Xue Ye Xue Za Zhi 2004; 25: 337-41.

19 Wu LX, Xu JH, Zhang KZ, Lin Q, Huang XW, Wen CX, et al. Disruption of the Bcr-Abl/Hsp90 protein complex: a possible mechanism to inhibit Bcr-Abl-positive human leukemic blasts by novobiocin. Leukemia 2008; 22: 1402-9.

20 van Os RP, Dethmers-Ausema B, de Haan G. In vitro assays for cobblestone area-forming cells, LTC-IC, and CFU-C. Methods Mol Biol 2008; 430: 143-57.

21 Meng A, Wang Y, Brown SA, Van ZG, Zhou D. Ionizing radiation and busulfan inhibit murine bone marrow cell hematopoietic function via apoptosis-dependent and -independent mechanisms. Exp Hematol 2003; 31: 1348-56.

22 Guan Y, Gerhard B, Hogge DE. Detection, isolation, and stimulation of quiescent primitive leukemic progenitor cells from patients with acute myeloid leukemia (AML). Blood 2003; 101: 3142-9.

23 Budak-Alpdogan T, Alpdogan O, Akoglu T. Morphological and functional characteristics of short-term and long-term bone marrow cultures in chronic myelogenous leukemia. Am J Hematol 1999; 62: 212-20.
24 Tretiakova I, Blaesius D, Maxia L, Wesselborg S, Schulze-Osthoff K, Cinatl $\mathrm{J} \mathrm{Jr}$, et al. Myrtucommulone from Myrtus communis induces apoptosis in cancer cells via the mitochondrial pathway involving caspase-9. Apoptosis 2008; 13: 119-31.

25 Tian Z, Shen J, Moseman AP, Yang Q, Yang J, Xiao P, et al. Dulxanthone $A$ induces cell cycle arrest and apoptosis via up-regulation of p53 through mitochondrial pathway in HepG2 cells. Int J Cancer 2008; 122: 31-8.

26 Del BB, Valentini MA, Comporti M, Maellaro E. Cisplatin-induced apoptosis in melanoma cells: role of caspase- 3 and caspase- 7 in Apaf-1 proteolytic cleavage and in execution of the degradative phases. Ann N Y Acad Sci 2003; 1010: 200-4.

27 Troiano L, Ferraresi R, Lugli E, Nemes E, Roat E, Nasi M, et al. Multiparametric analysis of cells with different mitochondrial membrane potential during apoptosis by polychromatic flow cytometry. Nat Protoc 2007; 2: 2719-27.

28 Hassan AQ, Sharma SV, Warmuth M. Allosteric inhibition of BCR-ABL. Cell Cycle 2010; 9: 3710-4.

29 Jatiani SS, Cosenza SC, Reddy MV, Ha JH, Baker SJ, Samanta AK, et al. A non-ATP-competitive dual inhibitor of JAK2 and BCR-ABL kinases: Elucidation of a novel therapeutic spectrum based on substrate competitive inhibition. Genes Cancer 2010; 1: 331-45.

30 Weisberg E, Deng X, Choi HG, Barrett R, Adamia S, Ray A, et al. Beneficial effects of combining a type II ATP competitive inhibitor with an allosteric competitive inhibitor of BCR-ABL for the treatment of imatinib-sensitive and imatinib-resistant CML. Leukemia 2010; 24: 1375-8.

31 Fabbro D, Manley PW, Jahnke W, Liebetanz J, Szyttenholm A, Fendrich $\mathrm{G}$, et al. Inhibitors of the Abl kinase directed at either the ATP- or myristate-binding site. Biochim Biophys Acta 2010; 1804: 454-62.

32 Passegue E, Wagner EF, Weissman IL. JunB deficiency leads to a myeloproliferative disorder arising from hematopoietic stem cells. Cell 2004; 119: 431-43.

33 Passegue E, Jamieson CH, Ailles LE, Weissman IL. Normal and leukemic hematopoiesis: are leukemias a stem cell disorder or a reacquisition of stem cell characteristics? Proc Natl Acad Sci U S A 2003; 100: 11842-9. 